\title{
Recall latencies of highly overlearned items'
}

NANCY C. WAUGH AND EDWIN C. HOLSTEIN ${ }^{2}$, DEPARTMENT OF PSYCHIATRY, HARVARD MEDICAL SCHOOL, MASSACHUSETTS GENERAL HOSPITAL, BOSton, Mass. 02114

An attempt was made to measure the stability of "long-term" memory for well-learned verbal associations. An analysis of recall latencies indicated that changes observed within the course of an experimental session are maintained over consecutive intervals of $24 \mathrm{~h}$

A newly learned association tends to be remembered more quickly each time it is tested within the course of an experimental session (Eimas \& Zeaman, 1963; Millward, 1964; Kintsch, 1965 Peterson, 1965; Suppes et al, 1966). The purpose of the present study was to see whether such a reduction in latency of recall is maintained over intervals of $24 \mathrm{~h}$. If so, then it may be that overlearned associations are in fact transferred (Theios, 1965 Suppes et al, 1966) to a rapid-access "permanent" memory store from some more temporary and less accessible system. If not, then the effect may simply denote a relatively temporary response set induced within the course of an experimental session (cf. Falmagne, 1965).

Method. The material to be recalled consisted of four lists of 25 paired associates, common English monosyllables selected at random. No word appeared in more than one list. Retention of a given list was tested over the course of five experimental sessions, one per day on Monday through Friday of a given week. A new list was memorized on each of four consecutive Mondays, so that each $\mathrm{S}$ served in a total of 20 experimental sessions.

The $S$ initially went through a list, one pair at a time and at her own pace, for a total of five study trials. She was instructed to take as much time as she wished to study the list, so as to insure that retention would be perfect on the first subsequent test trial. During the test trials, also self-paced, $\mathrm{S}$ recalled the second member of each previously memorized pair on seeing the first, having been instructed to do so as rapidly but also as accurately as possible.

The five study trials on Monday were followed immediately by five consecutive test trials. On Tuesday through Friday, $S$ first underwent five test trials and then one study trial followed by a sixth test. The order of both study and test items was varied unsystematically from trial to trial

The basic equipment consisted of an FPC-8 Flexowriter Programmatic Typewriter, a mechanical timer, a printout counter, and associated relay circuitry. The study and test lists were printed, one study pair or one test word to a line, on a long sheet of paper that was inserted into the carriage of the typewriter before every experimental session. $S$ viewed the paper through a mask that allowed her to see only one line at a time. Pressing the carriage return key resulted almost immediately in the exposure of the next item in a list. Responses were typed alongside test items. The apparatus was designed in such a way that the output of the printout counter measured the interval elapsing hetween the occurrence of a carriage return and the deflection of any other key on the Flexowriter. Thus a recall latency refers to the interval between S's activating the carriage return (thereby exposing a stimulus word) and her pressing the key corresponding to the first letter of a response word.

The Ss were two women undergraduates at Tufts University, skilled in typing by touch, who were paid for their services.

Results and Discussion. Mean recall latencies, estimated across items and lists, are shown in Fig. 1 as a function of the number of test trials. The data have been analyzed separately for the two Ss in view of the consistent differences between them. Each point is therefore based on a maximum of 100 observations. (Forgetting in fact occurred less than $1 \%$ of the time.) The points corresponding

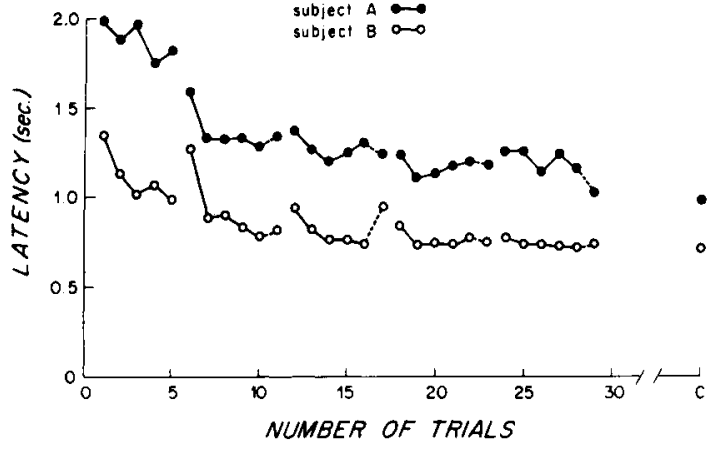

Fig. 1. Mean recall latency for a paired associate as a function of the number of times it was previously recalled.

to trials $11,17,23$, and 29 represent latencies recorded after an interpolated study trial. Each connected set of points refers to the data recorded on one day. The points plotted at the extreme right of the figure represent latencies recorded during a "calibration" procedure wherein $S$ had only to read a newly presented word and copy it down alongside itself.

It is obvious in Fig. 1 that recall latencies decrease markedly across Trials 1 through 7 (on Days 1 and 2), and to a lesser extent thereafter. There also appears to be a warm-up effect at the beginning of the first four sessions. Latencies appear to be affected very little, on the other hand, by a study trial interpolated prior to a recall trial at the end of a session. A week-by-week analysis of the data failes to reveal any appreciable practice effects.

These data appear to be consistent with the hypothesis that the repeated elicitation of a verbal response to a new cue can result in a stable change in the time taken to retrieve it from memory. Inspection of Fig. 1 reveals, in fact, that by trial $30 \mathrm{~S}$ 's recall latency is very close to the time that it takes to simply read a word and begin to copy it, a process that presumably does not include any intervening search of verbal memory.

\section{REFERENCES}

EIMAS, P. D., \& ZEAMAN, D. Response speed changes in Estes' pairedassociate "miniature" experiment. J. verbal Learn. verbal Behav., 1963, 1, 384-388.

FALMAGNE, J. C. Stochastic models for choice reaction time with applications to experimental results. J. math. Psychol., 1965, 2, 77-1 24.

KINTSCH, W. Habituation of the GSR component of the orienting reflex during paired-associate learning. J. math. Psychol, 1965, 2, 330-341.

MILLWARD, R. Latency in a modified paired-associate learning experiment. J. verbal Learn. verbal Behav., 1964, 3, 309-316.

PETERSON, L. Paired-associate latencies after the last error. Psychon. Sci., $1965,2,167-168$.

SUPPES, P., GROEN, G., \& SCHLAG-REY, M. A model for response latency in paired-associate learning. J. math. Psychol, 1966, 3, 99-128.

THEIOS, J. Prediction of paired-associate latencies after the last error by an all-or-none learning model. Psychon. Sci., 1965, 2, 311-312. NOTES

1. This work was supported by Research Grant No. MH-08119 from the National Institutes of Health, United States Public Health Service, to Harvard Medical School.

2. Now at the University of Pittsburgh Medical School. 